\title{
Abstracts of the First São Paulo Research Conference on "Molecular Medicine". Organized by the Dean for Research of the University of São Paulo, Brazil
}

The first "Sao Paulo Research Conference" on "Molecular Medicine" was held on November 14 and 15, 2003,

in Sao Paulo, Brazil. It was inserted in a course, which had the financial support of the Santander group and was sponsored by the Consejo Superiores de Investigaciones Cientificas from Spain and by the University of São Paulo. The conference on "Molecular Medicine" was an occasion for physicians and biologists to be exposed to the essential concepts in the field, delivered by internationally recognized clinical and basic investigators, from Brazil and

abroad. Examples of this approach were reviewed in cardiology, immunology, oncology, neurology, cell transplant technologies and related topics. Technological advances, new diagnostic tools and therapeutic agents were also discussed. Short communications in the form of posters were widely discussed. The corresponding abstracts are now presented. The Second "Sao Paulo Research Conference" will be devoted to "Mechanisms of Infection-Vaccins", and will occur in São Paulo as well, on December 2-4, 2004.

Information at bioconferences@eventus.com.br.

Scientific Committee of the First São Paulo Research Conference:

Prof. Jose Eduardo Krieger, INCOR, University of São Paulo, Dr. Mario J. Saad, Dept. of Medicine, University of Campinas, Prof. B. Boris Vargaftig, Institute of Biomedical Sciences, University of São Paulo, Prof. Marco Antonio Zago, Faculty of Medicine of Ribeirão Preto, University of São Paulo

Abstract Editors:

Dr. Wothan Tavares de Lima (wtdelima@icb.usp.br) and Prof. B. Boris Vargaftig, Dept. Pharmacology, Institute of Basic Biosciences, University of S. Paulo, Brazil.

\section{Costimulatory molecules expression on leukocytes from mice treated with crotapotin}

Flavia Garcia and Leonilda MB Santos

Dept. Microbiology and Immunology Neuroimmunology Unit, Biology Institute, University of Campinas, Sao Paulo P, Brazil

The venom of the South American rattlesnake Crotalus durissus terrificus (cdt) is a mixture of many proteins, including crotoxin (ctx), which is the major neurotoxic component of the venom. The crotoxin molecule is composed of two subunits, a basic, weakly toxic phospholipase A2 (PLA2) and an acidic, non-toxic subunit, known as crotapotin. We previously demonstrated that this acidic fraction of the venom reduced significantly the proliferative response of lymphocytes.

Using the proliferative response of lymphocyte assay and flow cytometry analysis we were able to demonstrate that the in vivo administration of crotapotin resulted in significantly reduction of the lymphocyte proliferative response to ConA and to Myelin basic protein in mice immunized with this neuroantigen. We were also able to demonstrate a significant reduction in the expression of the costimulatory molecule CD28. The CD28 molecule is constitutively expressed on $\mathrm{T}$ lymphocytes and $\mathrm{T}$ cell clones are activated by TCR binding to peptides and MHC molecules, with efficient costimulatory stimulation, otherwise these cells become anergic.

The crotapotin administration markedly reduces the expression of co stimulatory molecules CD28. These observations can explain, at least in part, the reduction of $\mathrm{T}$ lymphocyte activation.

Financial support: CAPES and FAPESP. 


\title{
Down-regulation of TNF-ALPHA and VEGF expression by SP1 decoy oligonucleotides in mouse melanoma tumor
}

\author{
Novak $\mathrm{EM}^{1}$, Metzger $\mathrm{M}^{2}$, Chammas $\mathrm{R}^{3}$, Costa $\mathrm{M}^{3}$, Dantas $\mathrm{K}^{1}$, Manabe $\mathrm{C}^{1}$, Pires $\mathrm{J}^{1}$, Oliveira $\mathrm{AC}^{1}$ and Bydlowski $\mathrm{SP}^{1,4}$ \\ ${ }^{1}$ Research and Molecular Biology Division, Pró-Sangue Hemocentro, São Paulo Foundation; ${ }^{2}$ Dept. of Physiology \& \\ Biophysics, Institute of Biomedical Sciences, University of São Paulo; ${ }^{3}$ Oncologia Experimental, Dept. of Radiology, Faculty \\ Medicine, University of São Paulo; ${ }^{4}$ Dept. of Hematology, Faculty Medicine University of São Paulo SP, Brazil
}

\begin{abstract}
Melanoma tumor growth and progression are highly dependent on adequate blood supply through angiogenesis. Since several genes involved in angiogenesis revealed potential binding sites for the transcription factor Sp1, we have examined the effects of local inoculation of Sp1 decoy oligodeoxynucleotides (ODNs) on the growth of transplanted murine melanoma tumors and the expression of VEGF and TNF-a within these tumors.

Adult female $\mathrm{C} 57 \mathrm{bl} / 6$ mice were injected with murine melanoma cells in the left and right legs. Palpable tumors appeared within 2 weeks. When tumor size had reached $0.5 \mathrm{~cm}^{3}$, animals received injections of either Sp1 decoy ODNs into the left or mutated Sp1 decoy ODNs into the right tumor. Animals were sacrificed after 7 cycles of treatment and the tumors were collected, fixed, and paraffin-embedded. Sections through the tumors were then either stained for HE or with an antibody to CD-34. HE stained sections were then analyzed for the fraction of necrotic areas and microvessel density was measured in the CD-34 stained sections using an image analysis system.
\end{abstract}

Treatment with Sp1 decoy ODNs, but not their mutated form, led to a significant increase $(P=0.041)$ of the tumor necrotic area, as evaluated morphometrically. Tumor necrosis was also associated with a decrease of microvascular density $(P=0.012)$ and relative vascular area $(P=0.026)$, as determined by counting CD-34 positive vascular structures within the tumor microenvironment of Sp1 decoy ODNs and control ODNs-treated tumors. RT-PCR experiments showed a strong decrease in the levels of $\mathrm{VEGF}_{188}$ and $\mathrm{VEGF}_{164}$ isoforms and a moderate decrease of TNF-a in Sp1 decoy ODNs-treated tumors.

Taken together, our results indicate that Sp1 decoy ODNs may inhibit angiogenesis by affecting the gene expression of key players in angiogenesis such as TNF-a and VEGF. These findings indicate that Sp1 decoy ODNs may be a potential new therapeutic tool in anti-angiogenic therapy.

Supported by: FAPESP.

\section{Changes in the gene expression profiling of the thymus in response to fibrosarcoma growth}

\author{
Passos GAS, Marques MMC, Junta CM, Cardoso RS, Mello SS, Donadi EA and Sakamoto-Hojo ET
}

Molecular Immunogenetics Group, Department of Genetics, Faculty Medicine of Ribeirão Preto, University of São Paulo, Ribeirão Preto, SP, Brazil

The aim of this study was to evaluate whether the subcutaneous injection into Balb-c mice of a transformed fibroblast cell line, which induces a fibrosarcoma at the site of injection, produces a differential gene expression profile in the thymus that might correlate with tumor growth.

Balb-c mice were subcutaneously injected with $10^{6}$ Ha-ras-1 oncogene transformed fibroblasts (B61 cells) and total RNA was prepared from the thymus of the tumor bearing animals. Sham-injected mice served as controls. The thymus RNA samples were used as templates for complex cDNA probe preparation and hybridization with a set of nylon micro arrays containing 1,576 IMAGE cDNA thymus sequences. The Cluster and Tree View and SAM programs were used to disclose induced and repressed genes by the thymus along tumor growth.

A dynamic transcriptional profile of the thymus in response to the tumor development was observed, using nylon cDNA micro arrays, containing 1,576 IMAGE cDNA thymus sequences. Genes related to DNA replication (primase), control of gene expression (CCAAT/enhancer binding protein), mRNA synthesis (RNA polymerase II), ribosomal protein genes, cell cycle and division (HMG-17 and CDK2), and control of protein catabolism (calpain) were differentially expressed. Many of these genes may be associated with the stimulation of thymocytes or other cell types in the thymus, by tumor antigenic components. In addition, the expressed sequence tags (ESTs) detected, that follow the same wave of expression of named genes, may also be correlated with similar biological functions. These data support the hypothesis that a transcriptional response of thymus immune cells is associated with cancer development, and that this response is correlated with specific mRNA expression profile that can be used as markers of the immune system, detecting the presence of tumor cells in vivo.

Financial support by FAPESP (99/12135-9 and 02/14098-8). 


\title{
Detection of t-cell receptor VB8.1-BD2.1 V(D)j recombination in murine fetal thymus organ culture
}

\author{
Cardoso RS, Junta CM, Macedo C, Sakamoto-Hojo ET and Passos GAS
}

Molecular Immunogenetics Group, Department of Genetics, Faculty of Medicine Ribeirão Preto, University of São Paulo, Ribeirão Preto, SP, Brazil

Functional analysis of T-cell development became possible after the introduction of in vitro fetal thymus organ culture (FTOC) in which the thymic microenvironment is mimicked. Since radiation affects T-cell development, the aim of the present study was to evaluate whether ionizing radiation modulates the VB8.1-BDJ2.1 V(D)J recombination in FTOC model and discover candidate genes to be involved in this process.

Fetal thymus from $13-15 p c$ Balb-c embryos was cultured for two days $(\mathrm{d}=2)$, mimicking the $15-17$ days of in vivo development. Thymus from $15 p c$ embryos was also cultured for 5 days $(\mathrm{d}=5)$, mimicking the in vivo development at the 20th day. The FTOCs were gamma irradiated ( 4 Gy) immediately after the culture establishment. Cell death was analyzed under epi-fluorescent microscopy technique to evaluate the FTOC viability. A PCR-based-method was applied to detect and quantify the VB8.1-BDJ2.1 recombination in FTOC and the differential RNA expression was evaluated using nylon cDNA micro arrays, containing 9,456 thymus IMAGE cDNA sequences.
The frequencies of normal, apoptotic and necrotic cells in FTOCs did not show significant alterations. The ionizing radiation did not influence the onset of $\mathrm{V}(\mathrm{D}) \mathrm{J}$ recombination, but it increased the amount of recombination in 5 dFTOC15pc. Micro array analysis showed that irradiated $5 \mathrm{dFTOC15pc}$ presented 10 genes repressed in comparison to the control, being 3 involved in cell growth/proliferation and 7 without known function. 21 genes were also detected as induced by the radiation. Thirteen of those genes have known function (3 DNA repair/recombination, 2 transcription inhibitors, 1 apoptosis, 3 signaling, 4 other) and 8 are unknown. In conclusion, while radiation did not induce alterations on the emergency of the rearrangements, it induced a significant increase in of VB8.1-DJ2.1 V(D)J recombination in 5 dFTOC $15 \mathrm{pc}$ embryos. Some genes were found as differentially expressed in those cultures and might be involved in the induction of $\mathrm{V}(\mathrm{D}) \mathrm{J}$ rearrangement by radiation.

Supported by: FAPESP (Procs. 99/12135-9 and 00/09994-9).

\section{Semi-quantitative analysis of differential expression of DP-2 trancription factor in pituitary adenomas}

\author{
Casarini $\mathrm{APM}^{1}$, Giorgi $\mathrm{RR}^{1}$, Cunha-Neto $\mathrm{MB}^{2}$, Bronstein $\mathrm{MD}^{2}$ and Giannella-Neto $\mathrm{D}^{1}$
}

\begin{abstract}
${ }^{1}$ Lab. for Cellular and Molecular Endocrinology - LIM 25 and ${ }^{2}$ Neuroendocrinolgy Unit. Hospital das Clinicas, Faculty of
\end{abstract} Medicine, University of São Paulo, São Paulo, Brazil

Pituitary adenomas comprise $10-15 \%$ of all intra-cranial neoplasias, mostly non-malignant in their biological behaviors; they can be associated to high morbidity and mortality due to mass effect on adjacent structures and/or inappropriate secretion of hormones. Recently, expression profile analysis by micro array technology revealed simultaneously hundreds of differentially expressed genes that might play a role in oncogenesis. DP-2 transcription factor was more intensively expressed in a metastasis of a nonfunctioning pituitary tumor when compared to non-functioning pituitary adenomas by hybridization on BD Atlas ${ }^{\mathrm{TM}}$ Human 1.2 Array membrane comprising Human Cancer Genes.

The present investigation was designed to confirm the magnitude of DP-2 transcription factor gene in nonfunctioning and ACTH, GH, and PRL-producing pituitary adenomas.

DP-2 mRNA expression was analyzed by semi-quantitative RT-PCR in 31 pituitary adenomas as follows: 1 ACTHoma, 5 PRLoma, 9 GHoma, 16 non-functioning adenoma and in a metastasis of a non-functioning carcinoma. The results were expressed in arbitrary units of optical density related to GAPDH mRNA expression as endogenous internal control and to the expression of 2 normal pituitaries.
DP-2 was similarly expressed in all types of pituitary tumors. There was a positive correlation between DP-2 mRNA expression and prolactin levels in plasma of patients with PRLomas $(r=0.99, p<0.05)$ and GHomas $(r=0.91$, $\mathrm{p}<0.05$ ). Also, a positive correlation was observed between DP-2 mRNA expression and tumor diameter only in PRLOmas $(\mathrm{r}=0.94, \mathrm{p}<0.05)$ and GHomas $(\mathrm{r}=0.78, \mathrm{p}<0.05)$.

DP-2 and DP-1 compose E2F molecules, which were identified as the final common target molecules that affect transcriptional activation of the c-myc gene stimulation by serum, PDGF, v-abl, bcr-abl, and PI3-kinase/c-akt many of which were shown to be related to oncogenesis in human tumors. Members of the retinoblastoma family proteins, including pRB and the related proteins p107 and p130, regulate E2F activity. Prolactin acts through its receptor that phosphorylates STAT1-3, which are required for the p130mediated full activation of the c-myc gene. The relationship between DP2 mRNA expression and tumor size in functioning PRLomas and GHomas probably depends on the activation of $\mathrm{STAT} 3 \rightarrow \mathrm{p}-130 \rightarrow \mathrm{E} 2 \mathrm{~F} / \mathrm{DP} 2 \rightarrow \mathrm{c}-\mathrm{myc}$ cascade. The central role-played by E2F and its correlation with cell proliferation and tumorigenesis makes it a promising target to control cellular proliferation in functioning pituitary tumors. 


\title{
Hypertonic solution ( $\mathrm{NaCl} 7.5 \%$ ) reduces mortality in experimental pancreatitis
}

\author{
Marcel CC. Machado ${ }^{1}$, Ana Maria de M. Coelho ${ }^{1}$, Vera Pontieri ${ }^{2}$, Sandra N. Sampietre ${ }^{1}$, Nilza AT. Molan ${ }^{1}$, Francisco G. \\ Soriano $^{2}$, Irineu T. Velasco ${ }^{1}$ \\ ${ }^{1}$ Departamento de Cirurgia e; ${ }^{2}$ Depto Clínica Médica- Emergências Clínicas - Faculdade de Medicina Universidade de São \\ Paulo. -São Paulo, Brasil
}

In spite of advances in the understanding of the pathophysiologic mechanisms of pancreatitis, the therapeutic interventions have not significantly modified clinical evolution and even less so mortality. Treatment of hemorrhagic shock with hypertonic solutions significantly reduces mortality. The hemodynamic effect of hypertonic solutions were first analyzed, and recently an anti-inflammatory effect has been described. Therefore, hypertonic solutions might be effective in the treatment of pancreatitis.

To study the effects of hypertonic solution treatment on rats with experimental pancreatitis, 31 male Wistar rats weighing 230-270 g were used. The left femoral artery and vein were catheterized, 24 hours prior to the induction of acute pancreatitis (AP), in order to monitor hemodynamic parameters and allow infusion. To induce pancreatitis, 2.5\% of sodium taurocolate was injected in the pancreatic duct. After this, the animals were divided into two groups: NS $(\mathrm{n}=17)$-received $34 \mathrm{ml} / \mathrm{Kg}$ saline $(\mathrm{NaCl} 0,9 \%)$ solution i.v. and $\mathrm{HS}(\mathrm{n}=14)$-received $4 \mathrm{ml} / \mathrm{Kg}$ hypertonic solution $(\mathrm{NaCl}$ $7,5 \%)$ i.v. Treatment was administered 1 hour after pancreatitis induction. Arterial blood pressure and cardiac rate were recorded before (baseline), and after 24 , and 48 hours. In the mortality study we followed the animals for 4 days.
Hypertonic solution prevented hypotension at 48 hours when compared to saline treatment as shown in table 1.

There was a significant reduction in mortality with hypertonic treatment; no mortality $(0 / 14)$, was observed in the HS group, whereas the NS group had a $35 \%(6 / 17)$ mortality $\left(\chi^{2}, \mathrm{p}<0.0133\right)$. Hypertonic solution as treatment for experimental pancreatitis thus showed promising results. The most significant result was the reduction in mortality from $35 \%$ to 0 . The prevention of hypotension seen at 48 hours may, in part, explain the reduction in mortality. However, the many other effects of hypertonic solution on inflammation must still be evaluated.

Table 1. Mean arterial blood pressure (MAP) and cardiac rate (CR) MAP (mmHg) CR (bpm)

\begin{tabular}{lcclll}
\hline & \multicolumn{2}{c}{ MP (mmHg) } & & \multicolumn{2}{c}{ CR (bpm) } \\
\cline { 2 - 3 } \cline { 5 - 6 } & NS & HS & & NS & HS \\
\hline Baseline & $105 \pm 2$ & $110 \pm 2$ & & $381 \pm 11$ & $398 \pm 14$ \\
24 hours after AP & $96 \pm 3$ & $101 \pm 2^{*}$ & & $366 \pm 9$ & $375 \pm 27$ \\
48 hours after AP & $91 \pm 3^{*}$ & $102 \pm 2^{*} \#$ & & $377 \pm 10$ & $360 \pm 28$ \\
\hline
\end{tabular}

* $p<0.05$ compared to baseline; $\# p<0.05$ compared to saline group values mean \pm sdm

\section{GST profile identifies prostate cancer risk in a brazilian population}

\author{
Mário Maciel de Lima Júnior ${ }^{2}$, Fabiana Granja ${ }^{1}$, Joseane Morari ${ }^{1}$, Luiz Eduardo Murgel de Castro Santos ${ }^{2}$, Lycurgo de Castro \\ Santos Neto ${ }^{2}$ and Laura S. Ward ${ }^{1}$
}

\footnotetext{
${ }^{1}$ Laboratory of Cancer Molecular Genetics - Dept. of Medicine, University of Campinas, São Paulo, Brazil; ${ }^{2}$ Dept of Urology-Irmandade de Misericórdia de Campinas, São Paulo, Brazil
}

The polymorphic inheritance of human drug-metabolizing enzymes, such as those encoded by the Glutathione-STransferase (GST) system, plays an important role in the development of most human cancers. Genetic polymorphisms have been demonstrated for GSTM1, GSTT1, and GSTP1 genes, that codify 3 GST enzymes considered important in humans. Individuals who are deletion homozygotes, classified as GSTM1 null or GSTT1 null, exhibit absence of enzymatic activity and are hypothesized to be at increased risk for the carcinogenic effects of a wide variety of environmental exposures. An aminoacid substitution $(1105 \mathrm{~V})$ in the GSTP1 gene results in two genotypes, $G S T P 1 A B$ and GSTP1BB. Those produce a variant enzyme with lower activity and less capability of effective detoxification of carcinogens than the wild type GSTP1AA. In order to look for the influence of GST enzymes inheritance pattern on prostate cancer risk we used a triplex PCR that included $\beta$-globin gene as a DNA quality control to study GSTM1 and GSTT1 and a PCR-SSCP-sequencing approach to study GSTP1 polymorphisms. We compared the genotypes of 83 patients including 53 prostate cancer cases and
30 benign prostatic hyperplasia (BPH) cases to 157 healthy control individuals. Data on lifetime occupational history, smoking history, general health conditions, previous diseases and other anamnestic data were obtained through interviews. Patients with prostate cancer showed a significant over-representation of the variants of the GSTP1 allele compared to the control population $(\mathrm{p}<0.0001)$. Prostate carcinoma patients presented a higher $(88.6 \%)$ prevalence of the combined null genotype for GSTM1 and GSTT1 than the normal population individuals $(11.3 \%)(p<0,005)$. The risk for prostate cancer in individuals with the variant GSTP1 enzymes, after adjusting for gender, age, tobacco and drugs use, was increased 11 times $(\mathrm{OR}=11.908$; CI: 4.956-28.614) and individuals with the GSTT1 and GSTM1 combined null genotype had 2.9 times $(\mathrm{OR}=2.9012$; CI: 1.0752-7.8281) higher risk for prostate cancer than the normal genotype population. We suggest that the GST genotype may be associated with an increased susceptibility to prostate cancer. GST profiling from peripheral blood may be a simple and useful tool in the screening for prostate cancer in the Brazilian population. 


\title{
High-level synthesis of recombinant murine endostatin in Chinese hamster ovary cells
}

\author{
Chura-Chambi RM, Tornieri PH, Spencer PJ, Nascimento PA, Mathor MB and Morganti L ${ }^{1}$
}

Molecular Biology Center, National Nuclear Energy Commission (IPEN-CNEN), Cidade Universitária, São Paulo, Brazil

\begin{abstract}
Angiogenesis, the formation of new capillaries from preexisting vessels, is a prerequisite for many physiological processes, including embryonic development, wound healing and female reproductive functions. On the other hand, a number of pathologic conditions such as cancer, rheumatoid arthritis and other chronic inflammatory diseases are characterized by excessive angiogenesis. Endostatin, a carboxy-terminal fragment of collagen XIII, has been shown to act as an anti-angiogenic agent, that specifically inhibits proliferation of endothelial cells and growth of various primary tumors. Here we describe the expression by chinese hamster ovary $(\mathrm{CHO})$ cells of murine endostatin and of a tagged fusion protein, (his) ${ }_{6}$-met-endostatin. A dicistronic mRNA expression vector was utilized in which endostatin cDNA was inserted upstream of the amplifiable marker gene, dihydrofolate reductase (DHFR). After transfection of the expression vectors, stepwise increments in methotrexate levels in the culture medium were applied,
\end{abstract}

promoting gene amplification and increasing expression levels of the proteins of interest. The expression levels of secreted native endostatin was about $78 \mu \mathrm{g} / \mathrm{mL}$ while the one for secreted (his) ${ }_{6}$-met-endostatin was about $114 \mu \mathrm{g} /$ $\mathrm{mL}$, for the best expressing clones. Characterization of physico-chemical and immunological activities of the proteins were performed using SDS-PAGE and Western blotting. The biological activities of recombinant endostatins were tested with a cow pulmonary artery endothelial (C-PAE) cell proliferation assay. Both recombinant endostatin and (his) ${ }_{6}$-met-endostatin inhibited, in a dose-dependent fashion, growth of C-PAE cells stimulated by basic fibroblast growth factor (bFGF).

This work was supported by Fundação de Amparo à Pesquisa do Estado de São Paulo (FAPESP), project 00/ 04658-0 (São Paulo, Brazil) and by Conselho Nacional de Pesquisa (CNPq).

\section{Proline homozygosity in codon 72 of p53 is a factor of susceptibility to thyroid cancer}

\author{
Fabiana Granja ${ }^{1}$, Joseane Morari ${ }^{1}$, Elaine C. Morari ${ }^{1}$, Luiz AC. Correa ${ }^{2}$, Lígia VM. Assumpção ${ }^{1}$ and Laura S. Ward $^{1}$ \\ ${ }^{1}$ Laboratory of Cancer Molecular Genetics - Dept of Medicine University of Campinas, São Paulo; ${ }^{2}$ Heliópolis Hospital, São \\ Paulo, SP, Brazil
}

A common germline polymorphism of $p 53$ gene produces an Arginine to Proline change at aminoacid position 72 . The resulting codon 72 variants have been reported in association with tumor susceptibility, since they reduce p53 ability to activate apoptosis. Codon 72 polymorphism may play a role in subsiding vulnerability to different carcinogens and might account for ethnic variations in cancer frequency. Using an allele-specific polymerase chain reaction, we tested peripheral blood samples from 98 patients with thyroid cancer, including 21 follicular (FC) and 77 papillary carcinomas (PC); 44 patients with benign nodules, including 14 follicular adenomas and 30 goiters; and 153 healthy individuals from the same geographical region. Data on lifetime occupational history, smoking history, general health conditions, previous diseases and other anamnestic data were obtained through interviews. Patients with FC $($ Pro $/$ Pro $=19,0 \%, \operatorname{Arg} / \operatorname{Arg}=42,9 \%, A r g / \operatorname{Pro}=38 \%)$ and with PC (Pro/Pro $=10,3 \%, A r g / \operatorname{Arg}=36,6 \%$, Arg $/$ Pro $=$ $53,4 \%)$ showed a significant overrepresentation of codon 72 variants compared to the control population (Pro/Pro $=$ $1,9 \%, \operatorname{Arg} / \operatorname{Arg}=33,3 \%, \operatorname{Arg} /$ Pro $=64,7 \%)(\mathrm{p}=0.0015)$. The Pro/Pro genotype, after adjusting for gender, age, tobacco and drugs was associated with a markedly higher risk of FC (OR- 9.714; CI:2.334-40.436) and PC (OR = 5.299; CI:2.334-40.436). These results provide evidence that $\mathrm{p} 53$ polymorphism is implicated in thyroid carcinogenesis and that individuals harboring the Pro/Pro genotype have an increased risk of developing thyroid cancer. 


\title{
A Novel GST class (GSTO1) gene profile identifies individuals with high risk for thyroid cancer
}

\author{
Fabiana Granja, Joseane Morari, Ligia VM. Assumpção and Laura S. Ward
}

Laboratory of Cancer Molecular Genetics, Dept. of Medicine University of Campinas, São Paulo, Brazil

Recently, a new class of the human Glutathione Stransferase gene family, named Omega (GSTO1), has been identified and shown to be expressed in a wide range of human tissues. The gene codifies an enzyme that appears to be involved in drug and xenobiotic metabolism. A variant of the GSTO1 gene produced by an amino acid substitution Ala140Asp produces an enzyme with lowered activities that could explain the variation between individuals in their susceptibility to oxidative stress. In order to investigate the role of GSTO1 enzymes inheritance pattern on thyroid cancer risk we used a PCR-SSCP-sequencing approach to compare the genotypes of 29 malignant nodules, including 17 papillary carcinomas (PC) and 12 follicular carcinomas (FC), to 11 benign nodules and to 60 healthy control individuals. Individuals with history of previous thyroid disease, exposure to radiation and antecedents of malignancy were excluded. Patients with PC and FC showed a significant over-representation of the variants of GSTO1 allele compared to the control population $(\mathrm{p}<0.0005)$. The risk for thyroid cancer in individuals with the variant GSTO1 enzymes, after adjusting for gender, age, tobacco and drugs use, increased 6 times (OR-6.0; CI: 2.09017.224). We suggest that GSTO1 genotype may be associated with an increased susceptibility to thyroid cancer. GSTO1 profiling from peripheral blood may be a simple and useful tool in the screening for thyroid nodule malignancy.

\section{The reduction of bacterial translocation in an acute pancreatitis experimental model after Pentoxifylline administration}

André S. Matheus, Ana Maria de M. Coelho, Sandra N. Sampietre, Lourenilson J. Souza, Cíntia Y. Morioka, Renato S. de Godoy, José Jukemura, José Eduardo M. Cunha, Marcel CC. Machado

Departamento de Cirurgia, Faculdade de Medicina da Universidade de São Paulo, São Paulo, Brasil

Bacterial translocation (BT) has been implicated in the development of multiple organ failure and is one of the major causes of pancreatic infection in patients with acute pancreatitis (AP). Pentoxifylline (PTX) is a derivative of methyl xanthine which displays beneficial effects in sepsis. The purpose of this study was to determinate if the BT can be reduced in severe AP after pentoxifylline administration.

An experimental model of severe AP by injection of 0.5 $\mathrm{ml}$ of $2.5 \%$ sodium taurocholate into the pancreatic duct was utilized. Thirty male Wistar rats were divided in 3 groups: Sham (surgical procedure without induction of AP), Pancreatitis (AP Induction), and Pentoxifylline (AP induction plus intraperitoneal administration of $25 \mathrm{mg} / \mathrm{kg}$ Pentoxifylline). We analyzed the occurrence of BT to the pancreas, mesenteric lymph nodes, liver, blood, and peritoneal cavity. BT was evaluated with bacterial cultures performed $24 \mathrm{~h}$ after the AP induction. The number of organisms were expressed in colony forming units (CFU) per gram.

Bacterial translocation was not observed in the Sham group. We observed bacterial translocation and a higher bacterial accumulation in the pancreas, mesenteric lymph nodes, blood, and peritoneal cavity in Pancreatitis group $(p<0.05)$. The Pentoxifylline group had a statistically significant reduction of BT in all analyzed tissues $(p<$ 0.05).

Severe AP increased BT. BT in AP is a complex process and involves many variables as a hematogenic, lymphatic, and transperitoneal bacterial dissemination. The administration of Pentoxifylline reduces bacterial translocation during experimental acute pancreatitis.

Supported by Grant: FAPESP 02/03773-6. 


\title{
Molecular biology and distribution of highly specific natural inhibitors of the angiotensin- converting enzyme
}

\author{
Hayashi $\mathrm{MAF}^{* 1}$, Lameu $\mathrm{C}^{* 1}$, Prezoto $\mathrm{BC}^{* 2}$, Pires $\mathrm{RS}^{3}$, Britto $\mathrm{LRG}^{4}$, Dive $\mathrm{V}^{5}$ and Camargo ACM*1 \\ ${ }^{1}$ Laboratory of Biochemistry and Biophysics, and ${ }^{2}$ Laboratory of Pharmacology, Instituto Butantan, SP; ${ }^{3}$ Laboratory of \\ Neurosciences II, Universidade Cidade de São Paulo, São Paulo; ${ }^{4}$ Dept. of Physiology and Biophysics, Institute of \\ Biomedical Sciences, University of São Paulo, SP; Brazil, Départment d'Ingénierie et d'Etudes des Protéines, CEA, Saclay, \\ Gif-sur-Yvette, France; *Center for Applied Toxinology (CAT-CEPID)
}

The bradykinin-potentiating peptides (BPPs) from Bothrops jararaca venom were the first natural inhibitors of the angiotensin-converting enzyme (ACE) described. Typically, the snake BPPs consist of pyroglutamyl proline-rich peptides of 5-13 amino acid residues. The antihypertensive properties of these peptides were crucial to demonstrate the pivotal role of the ACE in cardiovascular system. The structure-activity studies of the BPPs and analogs were essential for the development of the first nonpeptidic ACE inhibitor, the captopril. In the present study, we describe the genetic analysis of the BPPs precursors cloned from venom gland and brain of several snake species, which led to the identification of novel BPPs. Some of the BPPs deduced from these precursors are strong in vitro inhibitors of the ACE (nM range), while others display high specificity toward $\mathrm{N}$ - or C-domain active site of the somatic ACE, besides potentiating the bradykinin effects in ex vivo and in vivo experiments. The study of the BPPs structural diversity has been very important to understand the physiological role of these hypotensive peptides, and a new structurefunction analysis led to the selection of some of these natural peptides as anti-hypertensive drugs to be used in the treatment of human cardiovascular dysfunctions.

In addition, Northern blot and in situ hybridization studies revealed the presence of the BPPs precursor mRNAs in the Bothrops jararaca spleen and brain, in regions of the snake brain correlated to neuroendocrine functions such as the ventromedial hypothalamus, the paraventricular nuclei and organ. The co-localization and co-expression of the BPPs with the neuroendocrine regulator C-type natriuretic peptide, strongly suggest that BPPs belong to a novel class of endogenous vasoactive peptides.

Supported by: CAT-CEPID and FAPESP.

\section{"In silico" model for human sACE substrate binding: structural parameters defining $\mathrm{N}$ - and C-domain substrate specificity}

\author{
Hernandez $\mathrm{JF}^{1,2}$, Hayashi MAF${ }^{2}$, Neshich $\mathrm{G}^{1}$ and Camargo $\mathrm{ACM}^{2}$
}

\author{
${ }^{1}$ Structural Bioinformatic Laboratory, Campinas, Sao Paulo, Brazil; ${ }^{2}$ Center for Applied Toxinology, Instituto Butantan, Sao \\ Paulo, Brazil
}

The angiotensin I-converting enzyme (ACE) plays a key role in cardiovascular homeostasis and regulation of blood pressure by generating angiotensin II (A-II) and inactivates bradykinin. The somatic ACE (SACE) displays two active sites, one at the C-domain (SACEc) and another at the Ndomain (sACEn) of the protein. Distinct binding affinities for each domain were reported for substrates such as A-I and $\mathrm{Bk}$, and also for inhibitors such as the BPPs extracted from $B$. jararaca venom. In order to rationalize the design of specific inhibitors for each active site, molecular modeling and Molecular Dynamics (MD) techniques were used. We used MODELER for molecular modeling of the sACEnlisinopril complex with zinc and chloride cofactors. The enzyme-substrate complexes for "in silico" specificity studies were: modeled N- and C-domains of sACE and Bradykinin (BDK), Lisinopril (LPR) and Bradykinin Potentiating Peptide 9a (BPP9). The structures were docked using AutoDock and selected complexes were subjected to MD using GROMACS. The Java Protein Dossier was used for analysis of the molecular interactions in the complexes. The
SACE active sites are located in the center of the large internal channel. The carboxy-terminal side of the substrate-inhibitor is accommodated in the small C-chamber and the amino-terminal side in the large $\mathrm{N}$-chamber. 30 residues placed in the internal channel of the enzyme are involved in the accommodation of the BDK substrate. The lisinopril carboxy-terminal proline moiety is accommodated by the hydrophobic interactions with the aromatic ring of the $\mathrm{Tyr}_{532}, \mathrm{Tyr}_{529}$ and $\mathrm{Phe}_{521}$. These interactions are identified in the accommodation of the inhibitor $\mathrm{P}_{8}-\mathrm{P}_{9}$ residues in sACE-BPP9a complex, but the involved residues in the inhibitor accommodation in the $\mathrm{N}$ - and C-domains were different. In sACEn-BDK complex, the catalytic $\mathrm{Zn}$ ion is facing the $\mathrm{P}_{7}-\mathrm{F}_{8}$ substrate bond, in agreement whit the mechanism of catalysis. In sACEc-BDK complex, the substrate accommodation in 500 ps. MD was not favorable for catalysis, indicating differences in the substrate binding affinity in sACE N- and C-domains.

Supported by: CAT-CEPID and FAPESP. 


\title{
Leptin receptor and glucose transporter glut-4 in the heart of obeses adult wistar rats
}

\author{
Cherem $\mathrm{EHL}^{1}$, Paraguassú $\mathrm{PB}^{1}$, Moreira $\mathrm{ASB}^{1}$, Franco de Sá $\mathrm{CCN}^{1,2}$, Costa $\mathrm{CL}^{1}$ and Moura $\mathrm{AS}^{1}$ \\ ${ }^{1}$ Dept. of Physiological Sciences, State University of Rio de Janeiro, RJ and ${ }^{2}$ Department of Therapy Physics, Estácio de Sá \\ University, RJ, Brazil
}

Leptin, an hormone which is secreted by adipose tissues, is implicated in the control of satiation. It inhibits food intake, by reducing the expression of orexigenic hypothalamic neuropeptides. This system is impaired in obesity, because of increase of the hypothalamic resistance. Alternatively, It has been proposed the occurrence of an impaired leptin effect under insulin action in the heart tissue, with a possible impairment of GLUT-4 recruitment. The aim of this study was to evaluate the effects of obesity on the leptin receptor (OB-R) and on GLUT-4 in the heart tissue from obese 120 days old Wistar male rats.

Pups were exposed to early postnatal overfeeding by reducing litter size from normally $10-12$ to only 4 (OG: obese group), or maintained in normal litter size (CG: control group) until the 120th day post-birth. The heart was frozen and the leptin receptors and GLUT- 4 content were measured by immunobloting after membrane isolation and protein assay. Statistical significance of the results was determined using Student's $t$ test with $p<$ $0.05(n=6)$.

The OG showed a significant increase of body weight when compared with CG that was 20,48\% (OG: 458,05 \pm $30,1129 \mathrm{~g}$ and CG: $380,167 \pm 6,2034 \mathrm{~g}$, respectively, $\mathrm{p}<0,004)$. The GLUT- 4 content was augmented by $32 \%$ in the CG as compared to the OG, whereas the OB-R was increased in OG by $35 \%$ when compared to CG in the heart tissue samples.

These results show that obesity increases leptin receptor with a consequent decrease of the GLUT- 4 content in the heart. Therefore, our results suggest that obesity, throughout leptin, may alter the heart energetic metabolism by changing the insulin-signalizing pathway. This agrees with the existence of an adipo-insular axis that controls the heart metabolism.

Support: CNPq, FAPERJ and UNESA.

\section{Leptin and glycogen store in the heart tissue}

\author{
Cherem $\mathrm{EHL}^{1}$, Paraguassú $\mathrm{PB}^{1}$, Moreira $\mathrm{ASB}^{1}$, Franco de Sá $\mathrm{CCN}^{1,2}$, Costa $\mathrm{CL}^{1}$ and Moura $\mathrm{AS}^{1}$ \\ ${ }^{1}$ Department of Physiological Sciences, State University of Rio de Janeiro, RJ and ${ }^{2}$ Department of Therapy Physics, Estácio \\ de Sá University, RJ, Brazil
}

Previous studies have demonstrated that leptin induces impairment of insulin action in the heart. The objective of this study was to evaluate whether the association between leptin and insulin in obese heart induces change in the main fuel store of the heart, the glycogen.

Pups were exposed to early postnatal overfeeding by reducing litter size from normally $10-12$ to only 4 (OG: obese group), or maintained in normal litter size (CG: control group) until the day 120 post-birth. The cardiac glycogen was assayed by an enzymatic method (alfaamylase and glucose-oxidase). Leptin receptors and the glucose transporter GLUT-4 were measured by Western Blotting. Statistical significance of the results was determined using Student's $t$ test with $p<0.05(\mathrm{n}=6)$.

The OG showed a body weight increasing of $20,48 \%$ when compared with the CG (OG: $458,05 \pm 30,1129 \mathrm{~g}$ and CG: $380,167 \pm 6,2034 \mathrm{~g}, \mathrm{p}<0,004)$. The leptin receptors of OG were $35 \%$ higher than CG. For GLUT4 , the CG showed an increasing of $32 \%$ when compared to OG. The glycogen of the heart from OG and the CG was $0,618 \mathrm{mmol}$. and $1,07 \mathrm{mmol}$, respectively $(\mathrm{p}=$ $0,05)$. All data were presented as mean +SEM and percentage.

Obesity is associated to impaired insulin effects and higher leptin levels. We suggest that this impaired effect of insulin in the heart may be caused by leptin action. Therefore, the lowered glycogen and GLUT- 4 found in the heart of obese animals may be due a larger content of leptin receptors in the obese heart.

Support: CNPq, FAPERJ and UNESA. 


\title{
Molecular investigation of the stromal cell-derived factor-1 chemokine in lymphoid leukemia and lymphoma patients from Brazil
}

\author{
André ND, Cavassin GGO, Amarante MK, Oliveira CEC, Oliveira KB, Muxel SM, Miranda HC, Ariza CB, Watanabe MAE
}

Departamento de Ciências Patológicas, Universidade Estadual de Londrina, Londrina, Paraná, Brasil

The stromal cell-derived factor-1 (SDF-1) gene contains a common polymorphism, termed SDF1-3'A, in an evolutionarily conserved segment of the $3^{\prime}$ untranslated region. We compared SDF-1 genotypes in normal subjects and patients diagnosed with cancer.

The polymorphism variant, SDF1-3'Á eliminates the MspI restriction site. PCR-restriction fragment length polymorphism (RFLP) analysis was used for identification of genotypes.

We identified the heterozygous genotype $\left(3^{\prime} \mathrm{A} / \mathrm{wt}\right)$ in $38,8 \%(24 / 62)$ lymphoma patients and 26,1\% (11/42) lymphoid leukemia and 30\% (18/60) for normal individuals.

Although the heterozygous genotype in lymphoma patients was greater than that in normal subjects and lymphoid leukemia patients, there was no significant difference in the frequency of the $3^{\prime} \mathrm{A}$ allele across all three subject populations. Our study indicates that lymphoma patients in Brazil are more likely to carry 3'A gene than that in lymphoid leukemia, suggesting this genotype may be a different determinant for these forms of cancer.

\section{Aminopeptidase: a possible marker in hepatitis B virus infection}

\author{
Rettori MM, Montanaro-Oliveira SM, Freitas Jr, JO and Alves KB
}

Departamento de Bioquímica - UNIFESP-Escola Paulista de Medicina, São Paulo - SP, Brasil

During hepatitis B virus infection, the primary cause of hepatocelular damage is the activation of citotoxic $\mathrm{T}$ cells by the formation of new viruses and its associated antigens. The resulting necrosis and inflammation lead to an alteration in the hepatic metabolism. Aminopeptidases, enzymes that hydrolyze the N-terminal aminoacids of peptides and are responsible for protein metabolism, might have altered activity during hepatic pathologies. The aim of this study was to purify and characterize aminopeptidases present in hepatocytes infected by $\mathrm{B}$ virus. The homogenate was prepared from liver obtained during the necropsies of a female whose cause of death was hepatitis $B$ virus infection. The homogenate, treated with Triton X-100, was centrifuged at $6000 \mathrm{~g} / 4^{\circ} \mathrm{C} / 30 \mathrm{~min}$. The supernatant was submitted to an ion exchange chromatography (DEAE Cellulose Cellex D) equilibrated and washed with $20 \mathrm{mM}$ sodium phosphate buffer (NaPB), pH 7.0 and eluted with a linear gradient of 20 to $300 \mathrm{mM}$ of the same buffer, $\mathrm{pH}$ 7.0. Three peaks with aminopeptidase activity upon Ala-, Argand Leu-NA were eluted $\mathrm{H}_{0}, \mathrm{H}_{1}$ e $\mathrm{H}_{2}$, in condutances $160 \mathrm{uS}$,
700 uS e 1150 uS, respectively. $\mathrm{H}_{0}, \mathrm{H}_{1}$ e $\mathrm{H}_{2}$ were individually submitted to a hydrophobic interaction chromatography (Octyl Sepharose Fast Flow 4), equilibrated with $20 \mathrm{NaPB} / 3$ $\mathrm{M} \mathrm{KCl}, \mathrm{pH} 7.0$ and eluted with gradient of 3 to $0 \mathrm{M} \mathrm{KCl}$, followed with water and isopropanol $50 \%$. From $\mathrm{H}_{0}$, three peaks with aminopeptidase activity were eluted: $\mathrm{H}_{0}$ a $(24$ $\mathrm{mS}), \mathrm{H}_{0} \mathrm{~b}(5,1 \mathrm{mS})$ e $\mathrm{H}_{0} \mathrm{c}(110 \mathrm{uS})$, from $\mathrm{H}_{1}$, only one peak was obtained: $\mathrm{H}_{1}$ a $(15 \mathrm{mS})$, and from $\mathrm{H}_{2}$, two peaks: $\mathrm{H}_{2} \mathrm{a}$ (20 $\mathrm{mS})$ and $\mathrm{H}_{2} \mathrm{~b}(320 \mathrm{uS})$. The best substrate, given by the catalytic efficiency $\left(\mathrm{V}_{\text {máx }} / \mathrm{K}_{\mathrm{M}}\right)$ for $\mathrm{H}_{0} \mathrm{~b}$ and $\mathrm{H}_{0} \mathrm{c}$ was Leu-NA and for $\mathrm{H}_{1} \mathrm{a}$, Ala-NA. $\mathrm{H}_{1}$ a is a metallo-dependent enzyme, has not-SH group important for its activity and is inhibited by bestatin while $\mathrm{H}_{0} \mathrm{C}$ is not. Studies have identified a leucylspecific aminopeptidase not inhibited by bestatin (similar to leucyl-aminopeptidase $\mathrm{H}_{0} \mathrm{c}$ ) that is activated by IFN- $\gamma$ and is involved in antigen processing, modulating the citotoxic $\mathrm{T}$ cells response. Further work on this and others enzymes present may determine whether there are physical or chemical alterations in aminopeptidases in hepatic pathologies and if they might be used in laboratory tests. 


\title{
Factors that interfere with the insulin signaling pathways for the glucose transport
}

\author{
Marques SFG \\ Department of Surgery, Faculty of Medicine of Botucatu, University of São Paulo State, UNESP, Botucatu, Brazil
}

The insulin receptor belongs to the large family of receptors with intrinsic tyrosine kinase activity. Following insulin binding, the receptor undergoes autophosphorylation on multiple tyrosine residues resulting in activation of the receptor kinase and phosphorylation of insulin receptor substrate (IRS). The phosphorylation and interation protein-protein are pivotal for the transmission of the signal from the receptor to the final cellular effect, evidencing the translocation of vesicle containing GLUT- 4 of pool intracellular to the plasmatic membrane and activation of protein synthesis and glycogen.

The factors that might interfere in the insulin signaling pathway resulting in insulin-resistant and the type 2 diabetes were investigated.

In this revision were used the most pertinent articles on the mechanisms of interruption of the insulin signaling pathways for the intracellular glucose transport.
The phosphatidylinositol-3-phosphate (PI3- kinase) it presents an important paper in the translocation of GLUT-4. In obese individuals, insulin resistant and with diabetes, the activation of PI3-kinase for the insulin is reduced. The main defect in the signaling can be in proximal sequence for the activation of PI3-kinase due the reduction of insulin receptor phosphorylation and IRS-1 in these individuals.

Disturbances in the insulin function and secretion command, such as, the inhibition of receptor signaling, chronic increase of the concentration of the free fatty acids and glucose, and phosphorylation of receptor in serine, and contribute to the disturbed translocation of intracellular GLUT-4 and to the decrease of the phosphorylation of receptor in tirosine, resulting in insulin-resistant and, consequently, in type 2 diabetes.

\section{Role of aminopeptidases in the pathogenesis of steatosis}

\author{
Montanaro-Oliveira SM, Rettori MM, Freitas JO and Alves KB
}

Departamento de Bioquímica - UNIFESP - EPM, São Paulo, SP, Brasil

The altered lipidic metabolism in steatosis might be caused by diabetes mellitus, leading to fatty acid accumulation in the liver. These changes might modify protein metabolism in which aminopeptidases, enzymes that hydrolyze the $\mathrm{N}$ terminal aminoacid of peptides, are involved. The aim of this study was to purify and characterize the differents aminopeptidases presents in liver with steatosis. The homogenate treated with Triton X-100 was centrifuged ( $\left.6000 \mathrm{~g} / 4^{\circ} \mathrm{C} / 30 \mathrm{~min}\right)$ and the supernatant was submitted to an ion exchange chromatography (DEAE-Cellulose Cellex D) equilibrated and washed with $20 \mathrm{mM} \mathrm{NaPB}, \mathrm{pH} 7.0$ and eluted with a linear gradient of 20 to $300 \mathrm{mM} \mathrm{NaPB}, \mathrm{pH}$ 7.0. Two protein peaks with activity upon Ala-, Arg- and Leu-_naphthylamide (AA-NA) were eluted: $S_{1}(0,6 \mathrm{mS})$ and $S_{2}$
$(0,8 \mathrm{mS}) \cdot \mathrm{S}_{1}$ and $\mathrm{S}_{2}$ were submitted to a hydrophobic interaction chromatography in Octyl Sepharose Fast Flow 4 column, equilibrated with $20 \mathrm{mM} \mathrm{NaPB} / 3 \mathrm{M} \mathrm{KC1} \mathrm{M} \mathrm{KCl}$, $\mathrm{pH} 7,0$. From $\mathrm{S}_{1}$, during the gradient of 3 to $0 \mathrm{M} \mathrm{KCl}$, it was eluted only one active protein peak: $S_{1} a$ in $15 \mathrm{mS}$, and from $\mathrm{S}_{2}$ it was eluted two active protein peak: $\mathrm{S}_{2} \mathrm{a}(11 \mathrm{mS})$ and $\mathrm{S}_{2} \mathrm{~b}(0,4 \mathrm{mS})$. Catalytic efficiency shows that Leu- and AlaNA are the best substrates for $S_{1} a . S_{1} a$ is a neutral aminopeptidase, metallo-dependent, has - $\mathrm{SH}$ group important for its activity and is inhibited by bestatin. Previous studies showed that in healthy liver there is an aminopeptidase not retained in the ion exchange chromatography, different form liver with steatosis. This difference suggests that aminopeptidases may be used in laboratory test. 


\title{
$\mathrm{NO}$ and FasL are Required for eosinophil apoptosis induction by $\mathrm{PgE}_{2}$
}

\author{
Jones $\mathrm{C}^{1}$, Paula Neto $\mathrm{HA}^{2}$, Alves $\mathrm{L}^{1}$, Assreuy J ${ }^{3}$, Gaspar Elsas $\mathrm{MI}^{2}$ and Elsas $\mathrm{PX}^{1}$ \\ ${ }^{1}$ Departamento de Imunologia, UFRJ, Rio de Janeiro, Brasil; ${ }^{2}$ Intituto Fernandes Figueira, FIOCRUZ, Rio de Janeiro, Brasil; \\ ${ }^{3}$ Departamento de Farmacologia, UFSC, Santa Catarina, Brasil
}

In previous studies, our group has shown that prostaglandin $\mathrm{E}_{2}\left(\mathrm{PgE}_{2}\right)$ down-modulates the response of eosinophil precursors to IL-5 in bone-marrow cultures. We evaluated the effect of $\mathrm{PgE}_{2}$ on apoptosis of eosinophils differentiating from eosinophil precursors in IL-5-stimulated bonemarrow cultures.

Liquid cultures were established with IL-5, alone or in association with $\mathrm{PgE}_{2}$, S-nitroso-acetyl-DL-penicillamine (SNAP), Sodium Nitroprusside (SNP), N $\omega$-Nitro-L-Arginine (LNOArg) or Aminoguanidine (AmGua) and the frequency of eosinophils was determined at days 5 and 7. Apoptosis was evaluated by TUNEL and flow cytometry, at day 5 of culture.

There was significant induction of apoptosis in IL-5stimulated bone-marrow cultures from BALB/c mice in the presence of $\mathrm{PgE}_{2}$ at day 5 when compared to IL- 5 controls.
SNAP and SNP down-modulated eosinophil precursor responses to IL-5. In addition, SNAP induced apoptosis at day 5 in IL- 5 stimulated cultures. $\mathrm{PgE}_{2}$ down-modulated the response to IL-5, while AmGua or LNOArg blocked the effect of $\mathrm{PgE}_{2}$. Besides, $\mathrm{PgE}_{2}$ induced iNOS expression as early as 2 days of culture. $\mathrm{PgE}_{2}$ upregulated Fas and FasL expression in IL-5-stimulated bone-marrow cultures. In bone-marrow of gld mice neither $\mathrm{PgE}_{2}$ nor SNAP were able to down-modulate the response to IL-5, suggesting that the mechanism of apoptosis induction by these agents is mediated by FasL.

These findings show that $\mathrm{PgE}_{2}$ induces apoptosis in IL-5 stimulated bone-marrow cultures through a pathway involving NO and FasL.

Supported by: PAPES-FIOCRUZ, FINEP, CNPq.

\section{A possible relationship between anxiety, epilepsy and gabaergic neurotransmission}

\author{
Benedito MAC and Barbosa JGC
}

Departamento de Psicobiologia, UNIFESP, São Paulo, SP, Brasil

Emotional disturbances, e.g. anxiety, have high interictal incidence in the epilepsies. Gamma-aminobutyric acid (GABA) inhibitory neurotransmission in the brain is associated to both anxiety and epilepsy. Drugs inhibiting the ionotropic $\mathrm{GABA}_{\mathrm{A}}$ receptor are convulsants and anxiogenic, whereas the drugs which stimulate the receptor are anticonvulsants and anxiolytics. Tippocampus is a brain region involved in both emotions and epilepsies. $\mathrm{Na}^{+}-\mathrm{K}^{+}$ATPase repolarizes the neuron's membrane thus controlling tissue excitability. In the hippocampus $\mathrm{Na}^{+}-\mathrm{K}^{+}$-ATPase activity is influenced by GABAergic neurotransmission.

The aim of this work was to verify if rats susceptible to clonic convulsions induced by picrotoxin, a $\mathrm{GABA}_{\mathrm{A}}$ receptor chloride channel inhibitor, differ in anxiety and in the activity of hippocampal $\mathrm{Na}^{+}-\mathrm{K}^{+}$-ATPase.

Naive adult, males, Wistar rats were challenged with a dose of picrotoxin $(2.8 \mathrm{mg} / \mathrm{Kg}$, i.p.) which induces $50 \%$ of clonic convulsions. Two groups of rats were then formed, those having convulsions $(\mathrm{S}, \mathrm{n}=20)$ and those without signs of motor disturbances (NS, $\mathrm{n}=20$ ). Twenty days later $\mathrm{S}(\mathrm{n}=12)$ and $\mathrm{NS}(\mathrm{n}=12)$ rats were submitted to the elevated plus maze test (EPM) of anxiety. Other $S(n=8)$ and $\mathrm{NS}(\mathrm{n}=8)$ rats were sacrificed and the hippocampus dissected for the assay of $\mathrm{Na}^{+}-\mathrm{K}^{+}$-ATPase acitivity.

$S$ rats showed a statistically significant higher anxiety in the EPM test (\% time in the open arms: $S=5.2 \pm 1.8$, mean \pm SEM, NS: $18.4 \pm 4.2, \mathrm{p}<0.03, \%$ entries in the open arms: $S=14.8 \pm 3.8, \quad N S=27.7 \pm 4.7, p<0.05$, two-tailed Mann-Whitney $U$ test). A higher statistically significant activity of hippocampal $\mathrm{Na}^{+}-\mathrm{K}^{+}$-ATPase activity was detected in the $\mathrm{S}$ rats $(\mathrm{S}=150.8 \pm 2.5 \mathrm{nmol}$ of $\mathrm{p}$-nitrophe$\mathrm{nol} / \mathrm{mg}$ protein $/ \mathrm{min}$, mean $\pm \mathrm{SEM}, \mathrm{NS}=128.7 \pm 4.3, \mathrm{p}=$ 0.0009, two-tailed, Student $t$ test).

The data obtained suggest a relationship between anxiety and epilepsy involving inhibitory GABAergic neurotransmission and $\mathrm{Na}^{+}-\mathrm{K}^{+}$-ATPase control of brain excitability.

Supported by: AFIP. 


\title{
Turpentine-induced inflammatory reaction reduces the activity of aspirin-esterase in the plasma of male rats
}

\author{
Benedito MAC and Limaos EA
}

Departamento de Psicobiologia, UNIFESP, São Paulo, SP, Brasil

\begin{abstract}
Inflammation induces a cascade of molecular events, including COX 2 gene transcription. Aspirin (acetylsalicylic acid), the most used drug worldwide, has an antiinflammatory, antipyretic, analgesic and antithrombotic effect. Its mechanism of action resides on its capacity of acetylating the enzymes COX 1 and 2, inhibiting the synthesis of the precursors of the prostaglandins. The metabolism of aspirin initiates by its hydrolysis, promoted by esterases (aspirinesterases), yelding salicylic acid (SA) and acetate. A change on aspirin hydrolysis may lead to an alteration on its capacity to acetylate COX 1 and 2 . The aim of this work was to determine if inflammation induced experimentally would change the activity of aspirin-esterase in the plasma of rats.

Naive adults, males, Wistar rats were injected subcutaneously with turpentine $(n=7)$. Control rats received saline $(n=7)$. Blood from the tail vein was collected at 0 , 24, 48 and $96 \mathrm{~h}$ after the drug administration. Plasma was obtained after blood centrifugation. Aspirin-esterase was assayed fluorimetrically by measuring SA formed. Aspirin was used as the substrate at a $8 \mathrm{mM}$ final concentration in the assay. The results are expressed as nmol SA formed $/ \mathrm{mg}$ protein/min (mean $\pm \mathrm{SD}$ ).
\end{abstract}

The inflammatory reaction induced a statistically significant decrease (Two-way ANOVA for repeated measures, group $\mathrm{F}_{1,12}=21.07, \mathrm{p}=0.0006$; time $\mathrm{F}_{3,36}=14.04$, $\mathrm{p}=0.000003$; interaction $\mathrm{F}_{3,36}=14.27, \mathrm{p}=0.000003$, followed by Duncan's multiple range test for comparison among means, two-tailed) in the activity of plasma aspirin-esterase at 24, 48 and $96 \mathrm{~h}$ after drug injection when compared to the $0 \mathrm{~h}$ enzyme activity $[0 \mathrm{~h}$ : $0.86 \pm 0.09 ; 24$ h: $0.63 \pm 0.05 ; 48$ h: $0.60 \pm 0.08 ; 96$ h: $0.55 \pm 0.04, \mathrm{p}<0.00003]$ and time-matched control group [24 h:0.79 $\pm 0.08, \quad \mathrm{p}<0.0001 ; 48$ h: $0.80 \pm 0.12, \quad \mathrm{p}<$ $0.00003 ; 96 \mathrm{~h}: 0.78 \pm 0.08, \mathrm{p}<0.00005]$. There were no statistical significant differences among control means and between $0 \mathrm{~h}$ control $[0.79 \pm 0.04]$ and $0 \mathrm{~h}[0.86 \pm 0.09]$ treated groups.

The decrease in the activity of plasma aspirin-esterase may suggest a diminished expression of the protein, resulting in a higher concentration of the intact aspirin molecule, thus increasing its pharmacological action.

Supported by: AFIP.

\section{Identification of differentially expressed genes in parathyroid neoplasias}

\author{
Toscanini AC, Colin C, Festa F, Correa-Giannella MLC, Cunha-Neto MBC, Corrêa PH, Montenegro FLM, Cordeiro AC,
} Sogayar MC and Giannella-Neto D

Faculdade de Medicina da Universidade de São Paulo-SP, Brasil

Primary hyperparathyroidism is caused by a monoclonal single adenoma ( $80 \%$ of the cases), multiglandular parathyroid hyperplasia (15-20\% of the cases), and occasionally by parathyroid carcinoma. The molecular mechanisms underlying the development of these neoplasias is still unknown. Some genes may play a significant role in parathyroid tumorigenesis, such as PRAD1 and $\mathrm{Rb}$ or MEN-1 tumor supressor gene. However, these genetic changes do not precisely reflect the biological nature of tumor development. Therefore, analysis of expression profiles of a large number of genes in surgical specimens of parathyroid adenomas and carcinomas is an essential step toward clarifying the detailed mechanisms of carcinogenesis and identification of tumor markers.

In order to detect and identify differential gene expression in parathyroid tumors (adenoma versus carcinoma), we used three different methods. We performed a comparative genomic hybridization on a macroarray panel of 1536 genes (no matches whose sequences are well known) obtained by Human Cancer Genome Project and we employed cDNA array membranes with 190 oncogenes and tumor suppression genes (Atlas ${ }^{\mathrm{TM}} \mathrm{cDNA}$ Expression
Array Human Oncogene/Tumor Suppressor), and 1176 well-characterized human genes related to cancer and tumor biology (Atlas ${ }^{\mathrm{TM}}$ cDNA Expression Array Human Cancer 1.2. Clontech Laboratories, Inc. Palo Alto, Ca.). Finally, Representational Difference Analysis (RDA) was used for the cloning of differentially expressed genes. The hybridization of these membranes was performed with ${ }^{32} \mathrm{P}$ labeled cDNA probes synthesized from total RNA isolated from parathyroid adenoma and carcinoma.

The analysis of the panels revealed 46 genes expressed only in adenomas as: BCKD, IRF-1, TIMP3, STAT1, TPA, cyclin-D2 and THR, and 17 expressed only in carcinomas, including IGFBP3, IGFBP5, FGFR and PTC/RET. The RDA disclosed the identification and sequencing of 68 clones such as KIAA1199 protein, BAI-1, CEACAMPs and Ecadherin.

The RT-PCR analysis of the genes selected from the Atlas panel showed overexpression of IGFR-1 in carcinoma and low levels of bFGF in adenomas and hyperplasia when compared with the carcinoma. Further studies will be done in orther to investigate the function of RET, RAS and RAF genes in the role of parathyroid tumors. 


\title{
Comparative study of in vitro assays of chemotactic activity of venoms from neotropical social wasps
}

\author{
Cesar $\mathrm{LMM}^{1}$ and Palma MS
}

${ }^{1}$ Laboratory of Structural Biology and Zoochemistry - CEIS / Dept. Biology, IBRC, UNESP, Rio Claro-SP, Brazil

The social wasps venoms are constituted by many kinds of biologically active peptides, biogenic amines and proteins (mainly enzymes) that are able to cause pain, local edema and erythema. Some compounds of the venoms are responsible to eritrocyte hemolysis and leukocyte chemotaxis. This present work aimed to characterize the chemotactic effects of the venoms of nine species of the neotropical social wasps: Agelaia pallipes pallipes, Apoica cyanea, Brachigastra lecheguana, Myschocittarus drewsenii, Poliste lanio lanio, Poliste versicolor, Polybia ignobilis, Polybia paulista and Protonectarina sylveirae.

The nests of respectives wasps were collected and placed at $4^{\circ} \mathrm{C}$ during 5 hours. After that, the nest was opened. The wasps were killed and their venom reservoirs extracted by dissection. The venom content was extracted by washing the venom reservoirs with distilled water and then centrifuged at $5000 \mathrm{rpm}$ for $5 \mathrm{~min}$. The supernatant was collected and used in chemotaxis analysis. The chemotactic activity was assayed by using a chamber for leukocytes (collected in adult male Wistars rats) incubation. The venom of each species was placed on a lower compartment of the chamber while the leukocytes were incubated in the upper side of the chamber; this incubation lasted 2 hours at $36^{\circ} \mathrm{C}$, under nitrogen atmosphere. After the incubation, the chemotactic activity was observed by counting the leukocytes that migrated to the lower part of chamber. The counting was performed by using a Neübauer plate for cell counting, and compared to a control assays values, where the cells were incubated with saline.

We observed that only the wasps $P$. lanio lanio, $P$. ignobilis, P. paulista and A. pallipes pallipes presented chemotactic activity.

The capacity of wasps venoms promote leukocytes chemotaxis is related to the presence of the chemotactic peptides responsible to the attraction of leucocytes at the local bite. Concluding, among nine species studied, only four showed chemotaxis as effective part in their defensive arsenal. The other species may present other mechanisms for their defense, but not chemotaxis.

Supported by: CNPq.

\section{Phage display study using heart-infiltrating T-cell population rich in CD4 ${ }^{+}$isolated from rheumatic heart disease patients}

Bessa Juliana ${ }^{1}$, Giordano Ricardo $\mathrm{J}^{3}$, Faé Kellen ${ }^{1}$, Oshiro Sandra Emiko ${ }^{1}$, Pasqualini Renata ${ }^{3}$, Arap Wadih ${ }^{3}$, Kalil Jorge ${ }^{1,2}$ and Guilherme Luiza ${ }^{1}$

\footnotetext{
${ }^{1}$ Heart Institute-Incor, University of São Paulo School of Medicine; ${ }^{2}$ Division of Clinical Immunology and Allergy, Department of Clinical Medicine, University of São Paulo School of Medicine, São Paulo, Brazil; ${ }^{3}$ The University of Texas, M.D. Anderson Cancer Center, Houston, TX, USA
}

Rheumatic heart disease (RHD) is a serious consequence of throat infection with group A Streptococci (GAS). Molecular mimicry between streptococcal proteins and heart tissues has been proposed as the triggering factor for the disease. Consequently it is of great value to identify new antigens involved in RHD in order to better comprehend the mechanisms of disease progression, and to find ways of preventing its consequences

For this purpose, we have employed the phage display system. Peptides displayed on the surface of a phage particle have been widely used to identify important epitopes involved in inflammatory reactions, integrin binding sites among other applications. Using a method, named Biopanning and Rapid Analysis of Selective Interactive Ligands (BRASIL), which is based on a single centrifugation step to separate free phage particles from phage bound to the surface of live cells, we seek to find new peptides involved in chronic RHD reaction. Since several studies have suggested a pivotal role of $\mathrm{CD}^{+}{ }^{+}$T-cells in chronic
RHD disease, we selected heart-infiltrating T-cell lines (HIL), rich in $\mathrm{CD} 4+$, to investigate with the BRASIL methodology.

Firstly, phage library (CX10C-10 random amino acids flanked by Cys residues) was pre-cleared of unwanted peptides using normal donor mononuclear cells. Unbound phage was then transferred to heart-infiltrating T-cell lines (HIL) isolated from two different RHD patients and cell bound phage was then selected. In the present work, three different cell populations were used: (1) MASA $\left(79 \%\right.$ CD $4^{+}$ and $\left.0.6 \% \mathrm{CD}^{+}\right)$, (2) SLA $\left(87 \% \mathrm{CD}^{+}\right.$and $\left.7.4 \% \mathrm{CD}^{+}\right)$and (3) $\mathrm{CD}^{+}{ }^{+}$T-cell clone (TCR VB5JB2S7), isolated from SLA patient. Three successive rounds of biopanning have been performed, and randomly picked phage clones are being selected for sequencing and identification of displayed peptides.

Supported by FAPESP. 


\title{
Macrophage-influenza a virus interactions: the induction of TNF-a expression and its possible role on influenza pathogenesis
}

\author{
Espíndola $\mathrm{OM}^{1}$, Oliveira BCEPD ${ }^{1}$, Bozza $\mathrm{MT}^{2}$, Liberto $\mathrm{MIM}^{1}$ and Cabral MC ${ }^{1}$ \\ ${ }^{1}$ Lab. de Estruturas de Vírus Envelopados e Interferons, Dep. de Virologia; ${ }^{2}$ Lab. de Inflamação e Imunidade, Dep. de \\ Imunologia, IMPPG, UFRJ, Rio de Janeiro, Brasil
}

\begin{abstract}
Macrophages (Mf) are susceptible to infection with influenza A (Flu A) virus. This appears to be of biological importance, because the reaction of Mf to infection may create a suitable environment for immune response. The clinical picture of influenza, with high fever, malaise and inflamed tissue, indicates that proinflammatory cytokines, such as TNF-a, may play an important role in the initial phase of disease. Therefore, we decided to investigate the process of virus-M_ interaction by: (i) determining the efficiency of infection of murine J774G.8 $\mathrm{M}_{-}$, and (ii) analyzing the effects of the multiplicity of infection (MOI) and the trypsin treatment upon TNF-_ production by $\mathrm{M}_{-}$ infected with Flu A/X31 virus.

The infection efficiency of Mf cultures were established by comparing $\mathrm{CCID}_{50}$ titres to those obtained in MDBK and CEF cultures. The infectivity of the supernatantes from Flu A virus-infected $M_{-}$cultures were determined by inoculation into embryonated chicken eggs, and the concentration of TNF-_ detected by ELISA.
\end{abstract}

Our results showed that Mf_cultures present an infection efficiency smaller than that found for other cell types usually used for titration of Flu A virus samples, such as MDBK and CEF cultures. In addition, Mf synthesized noninfectious virus particles, although, in the presence of trypsin, they yielded low amounts of virions. The production of TNF-a correlated with the MOI, while the trypsin treatment activated the $M_{-}$and enhanced the secretion of TNF-a in Flu A virus- infected cultures. This effect could be detected $6 \mathrm{~h}$ post-infection (pi) and it was more evident in the cultures infected with low MOI. The peak of TNFsecretion by infected $\mathrm{Mf}\left(5 \times 10^{5}\right.$ cells $\left./ \mathrm{mL}\right)$, when treated or not with trypsin, reached $\sim 981 \pm 15 \mathrm{pg} / \mathrm{mL}$ after 24 hours.Based in these results, we suggest that the strong expression of TNF-a by Flu A virus infected-Mf disrupts the infection in vitro. Stress in the endoplasmic reticulum of these cells may be responsible for this phenomenon.

Financial Support: CNPq, UFRJ.

\section{Increased hepatic expression of insulin-like growth factor I receptor (IGF-IR) in chronic hepatitis C}

\author{
Stefano $\mathrm{JT}^{1}$, Cavaleiro $\mathrm{AM}^{1}$, Massarollo $\mathrm{PCB}^{2}$, Machado $\mathrm{MCC}^{2}$, Giannella MLCC ${ }^{1}$ and Giannella-Neto D ${ }^{1}$ \\ Laboratory for Cellular and Molecular Endocrinology (LIM-25) ${ }^{1}$. Laboratory for Experimental Surgery (LIM-37) ${ }^{2}$. Hospital \\ das Clínicas, FMUSP, Sao Paulo, Brazil
}

Chronic hepatitis C (CHC) promotes a slow but progressive deterioration of liver function and is the major cause of death from liver disease worldwide due to the high prevalence of complications such as cirrhosis and hepatocellular carcinoma. Liver is the organ with the highest levels of IGF-I expression, while exhibits almost undetectable levels of IGF-I receptor (IGF-IR) mRNA. This pattern of expression may be partially explained by down-regulation of IGF-IR promoted by locally produced IGF-I. IGF-IR plays an important role in cellular proliferation and in apoptosis prevention through different signal transduction pathways. Recent studies have demonstrated up-regulation of IGF-I and IGF-IR expression in rat liver tissues injured by $\mathrm{CCl}_{4}$ positively correlated with the development of hepatic fibrosis. Furthermore, IGF-I and its receptor apparently act as anabolic and stress-modulators in most cells, including those of the immune system.

Purpose: study the hepatic mRNA expression of IGF-I and IGF-IR genes in patients with $\mathrm{CHC}$.
Forty patients with $\mathrm{CHC}$ were selected according to clinical, serological, and biochemical criteria. A fragment of hepatic tissue was collected from all patients for liver biopsy, and IGF-I or IGF-IR gene expression was determined by semi-quantitative RT-PCR method.

An increased IGF-IR gene expression was detected in all patients with $\mathrm{CHC}$ in comparison to normal liver while no change was observed regarding IGF-I gene expression. There was a positive correlation between IGF-IR mRNA expression and the intensity/extension of lesions in porto-parenchymal interface (Person's $\mathrm{r}=0.40, \mathrm{p}<$ $0.05)$.

The increased mRNA expression of IGF-IR gene in the hepatic lesion related to $\mathrm{CHC}$ might be a compensatory reaction to the continuous loss of hepatocytes associated or not to the immunoreactions.

Supported by: FAPESP (98/13469-5). 


\title{
Exposure to 2-AAF promotes increased expression of hepatic oval cell markers
}

\author{
Leite AR, Corrêa-Giannella MLC, Fortes MAHZ, Cavaleiro AM and Giannella-Neto D \\ Setor de Endocrinologia Celular e Molecular (LIM-25) HC-FMUSP, São Paulo, Brasil
}

\begin{abstract}
Stem cells have the capability to differentiate into several cells types either in vitro or in vivo. The use of embryonic stem cells for medical purposes has been hampered by ethical questions, however, adult tissues stem cells are considered as equally important for replacement therapy. Hepatic oval cells are tissue stem cells found in the liver after inhibition of hepatocytes proliferation or following liver injury. Recent studies have shown that, in special culture conditions, these cells are capable to transdifferentiate in vitro into pancreatic endocrine cells, however, its use for diabetes mellitus treatment is not established. Proliferation of hepatic oval cells, which express the membrane protein Thy1.1, can be induced by 2 -acetamidofluorene (2-AAF) administration.

Purpose: to study the increase of hepatic oval cells proliferation in Wistar rats in response to 2-AAF treatment for subsequent cellular isolation and trans-differentiation in vitro.
\end{abstract}

Proliferation of hepatic oval cells was induced by daily administration of 2-AAF ( $25 \mathrm{mg} /$ day) during 2, 4, 7 and 9 days. Total RNA was isolated from livers removed from treated and untreated animals and Thy1.1 and HGF gene expression were detected by semi-quantitative RT-PCR.

A time-dependent increase in Thy1.1 and decrease in HGF gene expression was detected in Wistar rats treated with 2-AAF for 2, 4, 7 and 9 days when compared to control group.

A prolonged treatment with 2-AAF in Wistar rats promotes a decrease in the number of normal hepatocytes and consequently an increase on hepatic oval cells proliferation. A prolonged liver exposition to 2-AAF can potentiate the hepatic oval cell obtention for post cellular trans-differentiation in vitro.

Supported by: FAPESP.

\section{Expression of somatostatin receptors subtypes (SSTR1-5) in insulinomas}

\author{
Sá $\mathrm{SV}^{1}$, Pereira $\mathrm{MAA}^{2}$, Correa-Giannella MLC ${ }^{1,2}$, Souza JJS ${ }^{1,2}$, Machado MCC ${ }^{3}$ and Giannella-Neto $\mathrm{D}^{1,2}$ \\ ${ }^{1}$ Diabetes Unit (LIM-25); ${ }^{2}$ Division of Endocrinology and ${ }^{3}$ Division of Experimental Surgery, School of Medicine, University \\ of Sao Paulo, Sao Paulo, Brazil
}

The inhibition of GH, glucagon, insulin and gastrin secretion by somatostatin is mediated by a family of $\mathrm{G}_{\mathrm{i}}$-proteincoupled membrane receptors with five known subtypes, termed SSTR1-5, mostly distributed in anterior pituitary, gastrointestinal tract and pancreas. As the significant increase use of SST analogs for treating neuroendocrine tumors, a great purpose of interest is focused on the effects of long-term SST analogs pharmacotherapy on islet cell function. Since insulinomas are the most common pancreatic neurendocrine tumor, it is important to study the pattern of SSTR expression in insulinomas to caracterize the biological behaviour. The aim of this study was to analyze the expression of SSTRs $1-5$ by RT-PCR method in a tumor series of 18 insulinomas (two of them correspond to liver metastatic tissue) and to compare to clinical, histopathological and hormonal features.

Total RNA was extracted from fresh frozen tissue of each insulinoma. RNA integrity was determined by performing a PCR reaction for BCR constitutive gene.
The quantitative RT-PCR reaction was performed using primers from each SSTR gene and the BCR constitutive gene as interal control, in a co-amplification reaction.

RT-PCR analysis showed mRNA amplification of SSTR in _-cell tumors in a rank order of SSTR1 $>$ SSTR5 $>$ SSTR2 $>$ SSTR3 $>$ SSTR4. No statistically significant correlation was observed among SSTR expression and neither among glucose, c-peptide and insulin levels. In all cases, the preservation of total mRNA was ensured by detectable amplification of BCR mRNA.

Although it was observed a heterogeneous distribution of SSTR expression either in primary tumors and metastasis, the results showed an important correlation among tumor size and SSTR 3 and 5 expressions, indicating a possible use of specific analogues for SSTR3 and 5 (SOM230) to treat this neoplasm.

Supported by: FAPESP $n^{\text {os }}$ 00/08448-0 e 00/14674-3. 


\title{
Expression analysis of proto-oncogene ret in patients with primary hyperparathyroidism: comparison between hyperplasia, adenoma and carcinoma
}

\author{
Figueira PGM, Toscanini AC, Giannella MLCC, Montenegro FLM, Correa PHS, Giannella-Neto D
}

Faculdade de Medicina da Universidade de São Paulo-SP, Brasil

Primary hyperparathyroidism (pHPT) affects between 0.1 and $0.5 \%$ of population. pHPT of nonfamilial origin can be attributed to a benign, single adenoma in $80-85 \%$ of cases, to multiglandular parathyroid hyperplasia in 15-20\%, and occasionnaly to parathyroid carcinoma. The molecular mechanisms involved in the development of this neoplasias are still unknown and the traditional histopathological and morphological analysis do not accurately predict the biological behavior of these tumors. Few genes are certainly involved in parathyroid tumorigenesis, as cyclin D1/PRAD1 oncogene and the MEN1 gene. Using cDNA panels hybridized with radioactive probes from adenomas and carcinomas, we identified RET proto-oncogene overexpressed in parathyroid carcinomas when compared to adenomas. Literature shows that this gene is related to Multiple Endocrine Neoplasia type 2A, characterized by the occurence of medullary thyroid carcinoma (MTC), pheocromocytoma (PCC) and in some cases parathroid hyperplasia and to MEN type 2B, which is characterized by MTC, PCC and developmental abnormalities. The proto-oncogene RET is mutated in $90 \%$ of patients with MEN 2B.

In orther to analyse the expression of proto-oncogene RET in parathyroid tissue, we extracted total RNA from 15 adenomas, 2 carcinomas and 2 hyperplasias from patients with pHPT and sintetized complementary DNA using an RT-PCR approach. Two normal tissues were used to stabilish the amplification conditions and we chose BCR as the housekeeping gene.

The RT-PCR analysis confirm the panel results, demonstrating overexpression of proto-oncogene RET in carcinomas when compared to adenomas and hyperplasias. These results suggest that this gene could play an important role in parathyroid sporadic carcinomas.

\section{Down-modulation of acute myocarditis by Met-RANTES treatment: pivotal role of _-chemokines and their receptors in leukocyte migration into the heart of Trypanosoma cruzi-infected mice}

\author{
Marino APMP ${ }^{1}$, Silva AA ${ }^{1,2}$, Santos $\mathrm{PVA}^{1}$, Pinto $\mathrm{LMO}^{1}$, Gazzinelli $\mathrm{RT}^{3}$, Teixeira $\mathrm{MM}^{4}$ and Lannes-Vieira $\mathrm{J}^{1}$
}

${ }^{1}$ Lab. of Autoimmunity and Immunoregulation, Dept. of Immunology, IOC-Fiocruz, RJ; ${ }^{2}$ Dept. of Pathology, UFF, Niterói, Rio de Janeiro, Brazil; ${ }^{3}$ Lab. of Immunopatology, CPqRR-Fiocruz, Belo Horizonte, Minas Gerais, Brazil; ${ }^{4}$ Dept. of Biochemistry and Immunology, UFMG, Belo Horizonte, Minas Gerais, Brazil (MMT)

The understanding of the pathogenesis of Trypanosoma cruzi-elicited myocarditis is crucial to delineate strategies to ameliorate the inflammation that leads to severe heart dysfunction. The augmented expression of RANTES (CCL5) and MIP1-_ (CCL3) in the heart of acutely and chronically T. cruzi-infected mice suggests a role for CC or _ chemokines and their receptors in the pathogenesis of $T$. cruzi-elicited myocarditis (Talvani et al., 2000; Dos Santos et al., 2001). In the present study, we report that when $\mathrm{C} 3 \mathrm{H} /$ He mice were infected with 100 trypomastigotes of the Colombiana strain of $T$. cruzi most of the inflammatory cells present in the heart express CCR5, a CCL5 and CCL3 receptor. Further, peripheral blood $\mathrm{CD}^{+}{ }^{+} \mathrm{T}$ lymphocytes display an increased expression of CCR5. These findings led us to use Met-RANTES, a methionylated human RANTES that inhibits agonist activity at CCR1 and CCR5 (Proudfoot et al., 1996), to modulate the establishment of early acute $T$. cruzi-elicited myocarditis. Met-RANTES treatment does not interfere with parasitism, however significantly decreases the numbers of $\mathrm{CD}^{+}$and $\mathrm{CD}^{+}{ }^{+} \mathrm{T}$ cells, and of $\mathrm{TNF}_{-}{ }^{+}$ (30\%) and, prominently, of IL- $4^{+}(70 \%)$ cells infiltrating the cardiac tissue. In addition, the deposition of fibronectin is also reduced in Met-RANTES-treated mice. Moreover, MetRANTES treatment results in increased survival of T. cruziinfected animals when compared to saline treatment. These results indicate that the massive influx of CCR5-bearing inflammatory cells into the heart tissue is not crucial for cellmediated anti-T. cruzi immunity, however it seems to be critical for pathogenesis of $T$. cruzi-elicited myocarditis. Thus, _ chemokine receptors might become an attractive therapeutic target for further evaluation during T. cruzi infection.

Supported by: FAPERJ, PAPES-2, CNPq, CAPES, IOC-Fiocruz. 


\title{
Possible role of antibodies that recognise myelin basic protein during Trypanosoma cruzi infection: they involved in pathogenesis or protective autoreactivity?
}

\author{
Silva $\mathrm{AA}^{1,2}$, Martins $\mathrm{DR}^{1}$, Roffê $\mathrm{E}^{1}$ and Lannes-Vieira J \\ ${ }^{1}$ Lab. of Autoimmunity and Immunoregulation, Dept. of Immunology IOC, Fiocruz, Rio de Janeiro; ${ }^{2}$ Dept. of Pathology, \\ UFF, Niterói, Rio de Janeiro, Brazil
}

\begin{abstract}
Antibodies specific for myelin basic protein (MBP) have been detected in sera of infected non-human primatas and human and Trypanosoma cruzi-infected mice. To study the participation of these antibodies in the pathogenesis of CNS lesions, $\mathrm{C} 3 \mathrm{H} / \mathrm{He}$ and $\mathrm{C} 57 \mathrm{BL} / 6$ mice were infected with T.cruzi. In the acute phase, the $\mathrm{C} 3 \mathrm{H} / \mathrm{He}$ mice showed intense encephalitis mainly composed of $\mathrm{F}_{4} / 80^{+}$and $\mathrm{CD}^{+} \mathrm{T}$ cells. Antibodies recognising MBP and its encephalitogenic fragment were detected 28 days post-infection, contrasting with low levels of anti-T.cruzi antibodies and absence of polyclonal activation. During the late acute and chronic phase, high levels of anti-MBP antibodies persisted and paralleled the levels of total IgG and anti-T.cruzi antibodies. In contrast, $\mathrm{C} 57 \mathrm{BL} / 6$ mice showed rare inflammatory infiltrates restricted to the acute phase and low levels of anti-MBP antibodies were detected only during chronic phase. When sera of T.cruzi-infected mice were absorbed with T.cruzi antigens immunoreactivity against MBP was partially abrogated, suggesting the existence of cross-reactivity between MBP and parasite antigens. Corro-
\end{abstract}

borating this idea, reactivity against MBP from sera of MBPimmunized mice was also inhibited by previous incubation with T.cruzi antigens. In order to approach the biological role of the anti-MBP antibodies, mice were immunized with MBP and challenged with T.cruzi. Preliminary results show that immunized-infected $\mathrm{C} 3 \mathrm{H} / \mathrm{He}$ mice exhibited high level of parasitemia at $63 \mathrm{dpi}$ contrasting with T.cruzi-infected $\mathrm{C} 3 \mathrm{H} / \mathrm{He}$. Interestingly, immunized-infected $\mathrm{C} 57 \mathrm{BL} / 6$ mice showed a delay in the parasitemia peak. Important, when investigated the isotype of anti-T.cruzi and anti-MBP antibodies in sera of both mice, we observed in chronic phase IgG1 and IgG2a high levels of anti-MBP and antiT.cruzi antibodies exclusively in $\mathrm{C} 3 \mathrm{H} / \mathrm{He}$ mice. In addition, $\mathrm{C} 57 \mathrm{BL} / 6$ serum showed significantly high levels of IgG2b anti-MBP antibodies during the course of infection. These results suggest that anti-MBP antibodies may play an immunoregulatory role during T.cruzi infection.

Support by: IOC-Fiocruz, PAPES-II, FAPERJ, CNPq.

\section{Use of nested-Pcr and monoclonal antibodies for diagnostic of human respiratory syncytial vírus (HRSV) in community hospital in botucatu, SP}

\author{
Bosso PAR, Kosaka IM, Candeias JMG, Moraes MA and Ventura AM
}

\begin{abstract}
Depto de Microbiologia e Imunologia do Instituto de Biociências-UNESP-Botucatu, SP; Depto de Pediatria da Faculdade de Medicina, Botucatu, SP; Depto de Microbiologia do Instituto de Ciências Biomédicas-USP. São Paulo-SP, Brasil
\end{abstract}

\begin{abstract}
Human Respiratory Syncytial Virus (HRSV) is well recognized as the single most important pathogen accounting for acute viral infection of the lower respiratory tract in infants and young children. Early and differential diagnosis of HRSV infections is necessary for infected infants monitoring, nosocomial spread prevention, and, in some cases, to guide a possible adapted antivirus therapy choice. The samples were collected from children attended at the emergency service, pediatric wards and intensive care unit
\end{abstract}

presenting acute respiratory symptoms below 2 years of age HRSV. It was found in $18 \%$ of the 84 samples positive by Imunnofluorescence and RT-PCR. HRSV subgroup A and B co-circulated within the same period. It was found to be more frequent between June and July. These data confirms the usual HRSV sazonality of subtropical countries.

Financial Support: FAPESP and CNPq 


\title{
Construction of adenoviral vectors expressing $F$ and $G$ glycoproteins of human respiratory syncytial virus (HSRV)
}

\author{
Ithana Monteiro Kosaka, Cassiano Carromeu, Edison Luiz Durigon and Armando Morais Ventura
}

Departamento de Microbiologia, Instituto de Ciências Biomédicas, Universidade de São Paulo, SP, Brasil

\begin{abstract}
Human Respiratory Syncytial Virus (HRSV) was first characterized in 1957 and has since been recognized as the most common viral cause of severe respiratory tract infection in young infants worldwide. Despite many years of research there is still no effective treatment or any immediate prospect of a vaccine. The RSV genome is composed of single stranded negative sense RNA and the virion consists of a nucleocapsid packaged within a lipid envelope. The envelope contains spike-like projections, each being a homo-oligomer of one of three transmembrane viral envelope proteins: the attachment protein $G$, the fusion protein $\mathrm{F}$ involved in viral penetration and the small hidrofobic protein $\mathrm{SH}$. The aim of this work was to construct two recombinant replication-defective adeno-
\end{abstract}

viruses carrying separately $\mathrm{F}$ and $\mathrm{G}$ genes from HRSV. This system was chosen because adenovirus delivers genes into target cells with high efficiency in a variety of cell lines and can be used in vitro and in vivo. In order to obtain the recombinant viruses, we did RT-PCR of RNA extracted from the HRSV A2 strain, the genes $\mathrm{F}$ and $\mathrm{G}$ were cloned in to pAdeno- $X$ vectors. pAdeno- $F$ and pAdeno- $G$ were transfected in HEK-293 cells for the production of recombinant viruses, that expressed efficiently these two proteins and provide us the means for doing functional assays and immunization tests.

Financial Support: FAPESP and CNPq.

\section{Obtaining of a fragment of canine recombinant angiostatin}

Barros CC, Ramalho JDS, Machado MFM, Barrabas N, Pesquero JL and Pesquero JB and Araújo RC

\author{
CIIB, University of Mogi das Cruzes; Depth of Biophysics, UNIFESP, São Paulo, Brazil
}

Antiangiogenesis is a new therapeutic strategy for the treatment of several pathologies as ophthalmic diseases, arthritis, hypertrophic scarring and tumor. Tumor growth and metastasis are angiogenesis-dependent. The neovascularization is regulated by pro- and anti-angiogenic factors. Angiostatin is certainly one of the most potent described anti-angiogenic factors. It is an endogen protein derived from plasminogen, a circulatory protein that displays 5 internal portions denominated "kringles". Angiostatin is formed by the first 4 "kringles". The fragment containing the first three "kringles" is considered to be more potent in inhibiting angiogenesis than angiostatin.

Purpose: To obtain the fragment corresponding to the first two canine "kringles" from plasminogen.

Total RNA of canine liver was extracted and used in a reaction of reverse transcription for obtaining the cDNA. With the use of specific primers, we amplified the area corresponding to the first two "kringles". This DNA was inserted into a pGEM-T vector and cloned in Escherichia coli. The maxi-prep was done and the material was sequenced. After those steps, we compared our sequence with that deposited in the GeneBank. The DNA was subcloned into pPIC9 vector that was used to transform yeast Pichia pastoris (GS115) by electroporation. We used methanol to activate the AOX1 promoter and to induce the production of the protein in shaker. The cells of the fermentation product were centrifuged, separated and the supernatant was dialyzed, concentrated and analyzed through electrophoresis in SDS-PAGE gel.

The product of RT-PCR analyzed in agarose gel showed a band of approximately $600 \mathrm{bp}$. The result of the sequencing of our DNA demonstrated 100\% of analogy with the sequence of GeneBank. Analysis through PCR checked the insert of sequence in the yeast DNA genomic. Analyzing it fermented in SDS-PAGE visualized a band of $18 \mathrm{kDa}$ nonexistent in the negative clone.

We amplified the part of DNA correspondent to two first "kringles" of the canine plasminogen and we inserted that gene in the DNA genomic of the yeast $P$. pastoris. Future experiments are needed to confirm the expression of that recombinant protein. 


\title{
Human contamination by heavy metals. case: a study in São Paulo
}

\author{
Aurea Eleutério Pascalicchio
}

Departamento de Epidemiologia, Instituto de Saude da secretaria de Saude, São paulo, Brasil

Environmental degradation has taken planetary proportions. Toxic metals may constitute a severe public health problem as well as an individual disease. The increased life expectancy and the chronic-degenerative conditions, changes in the world morbidity and mortality profile comprise the scenario. It will demand an immediate response for new methodological references and studies. Genetics and the principles of biomolecular medicine have provided ground for research and a conceptual revolution. The importance of bio-accumulation and its generally longterm effects should be pointed out.

Hair is a worldwide recognized biological indicator of metal contamination.

Hairs were collected from 71 healthy individuals in São Paulo, Brazil.A structured questionnaire to correlate stress, dietary habits and life styles with possible biochemical alterations was applied. Indicators were created. Multivariate statistical analysis were used. 84,5\% of the sample,a high level of contamination, was obtained.

The most frequent metals founded were mercury, aluminium, silver, lead, nickel and tin, and multiple contaminations were also detected. Correlation between metals and habits surveyed showed no statistical significance, probable because there was no follow-up and the size of the sample was not sufficient. The effects studied occur due to long-term bioaccumulation. The question of what may be happening to groups at risk or to the general population remains and needs further studies.

\section{Molecular stratification of rheumatoid arthritis (RA) patients based on large scale gene expression profile}

\author{
Junta $\mathrm{CM}^{1}$, Victorero $\mathrm{G}^{3}$, Loriod $\mathrm{B}^{3}$, Nguyen $\mathrm{C}^{3}$, Donadi $\mathrm{EA}^{1}$ and Passos GAS ${ }^{1,2}$ \\ ${ }^{1}$ Faculty of Medicine, University of São Paulo, Ribeirão Preto, SP, Brazil; ${ }^{2}$ Faculty of Dentistry, Ribeirão Preto, SP, Brazil; \\ ${ }^{3}$ INSERM of Marseille, France
}

Rheumatoid arthritis (RA) is a systemic and chronic inflammatory disease affecting joints and articulations. While its etiology is still unknown, some observations are important: 1) RA has a strong genetic influence, 2) It is initiated by a reaction that can be triggered by microbial antigen stimulus, 3) It can be caused by an inappropriate autoimmune response to self-components and 4) It may result from the interaction between two or more of these factors. To observe how the lymphocytes of RA patients are transcriptionally modulated (control of synthesis and abundance of individual mRNA molecules) as a result of the factors above mentioned, we used the cDNA-array technology, which has permitted to quantify the expression levels of hundreds of genes. By means of bioinformatic tools, the RA patients were stratified according to the individual gene expression profile.

Purpose: To evaluate the quantitative differential gene expression of lymphocytes and to stratify RA patients presenting different disease severity.

A panel of 1,248 PCR products from cloned human cDNAs obtained from the IMAGE Consortium was spotted on nylon membranes. The ${ }^{33} \mathrm{P}-\mathrm{cDNA}$-arrays probes were prepared from total RNA of peripheral blood lymphocytes (PBL) of RA patients. Gene clustering based on expression profiles was performed using the Cluster and TreeView software.

A total of 47 genes were identified as differentially expressed among RA patients. Decreased expression of DNA methylation genes was shared in RA patients, whereas matrix metalloproteinase gene (MMP3) expression was higher in severe than moderate disease. DNA repair and cell cycle genes were also differentially expressed according to the disease severity.

While the etiology of RA remains uncertain, the PBL of these patients are genetically modulated presenting a differential transcriptional profile permitting a stratification of the patients according to disease severity and clinical features of RA.

FAPESP (01/09519-1), (99/12135-9), INSERM-FAPESP (98/ 09789-4). 


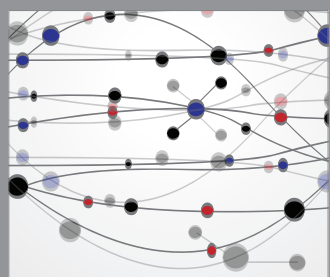

The Scientific World Journal
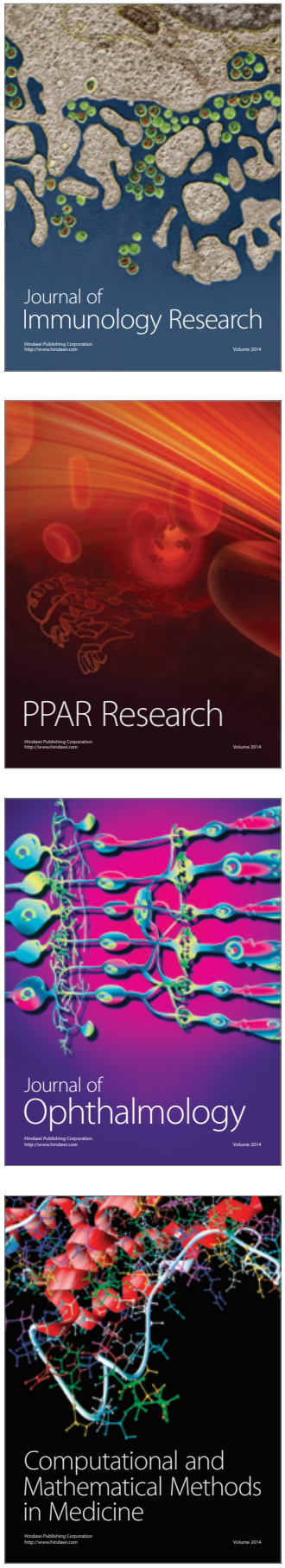

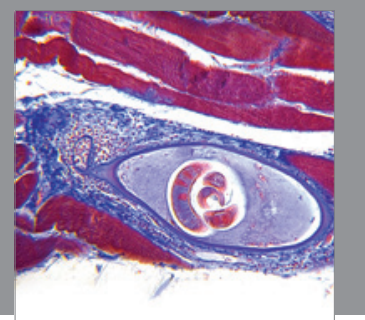

Gastroenterology

Research and Practice
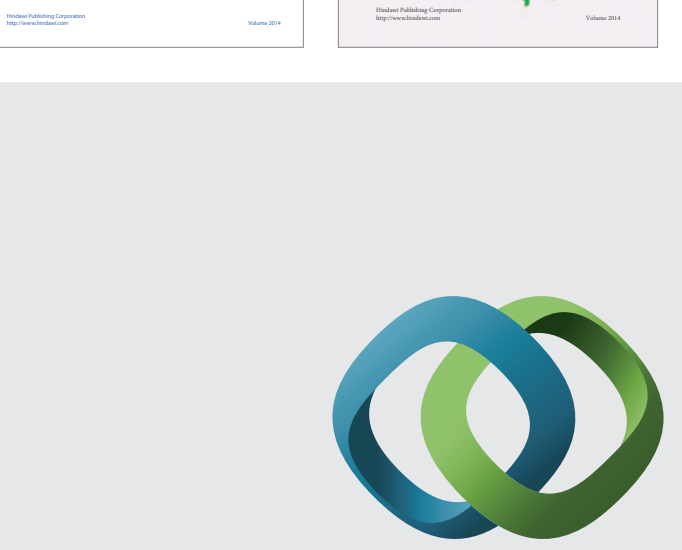

\section{Hindawi}

Submit your manuscripts at

http://www.hindawi.com
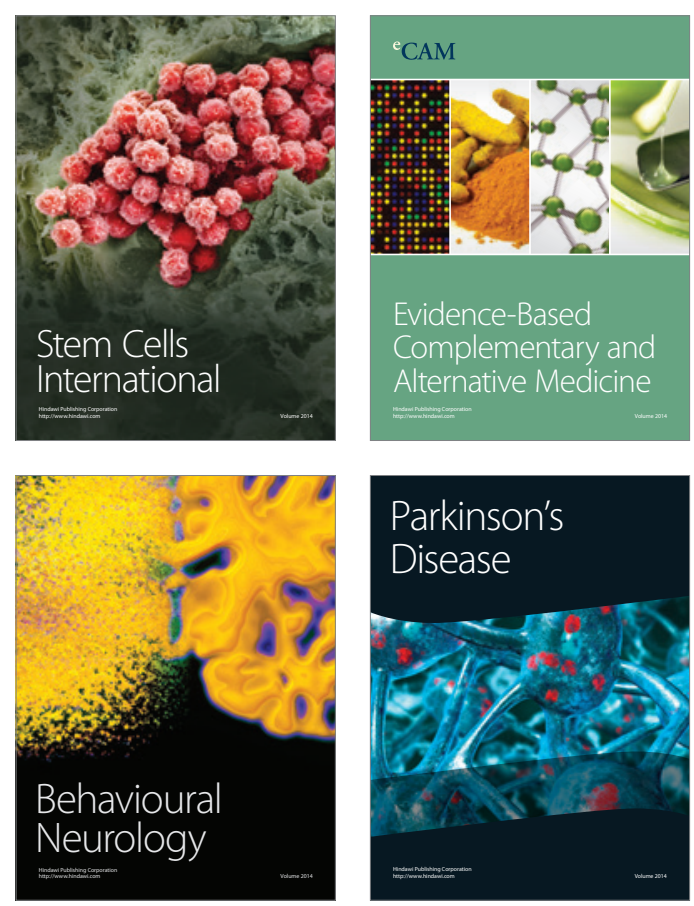

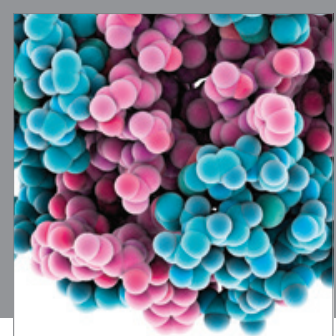

Journal of
Diabetes Research

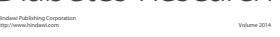

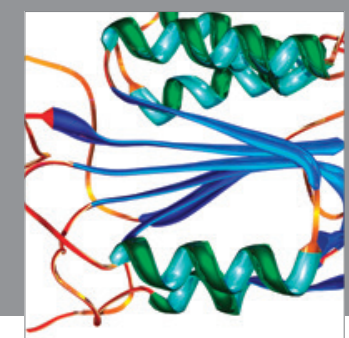

Disease Markers
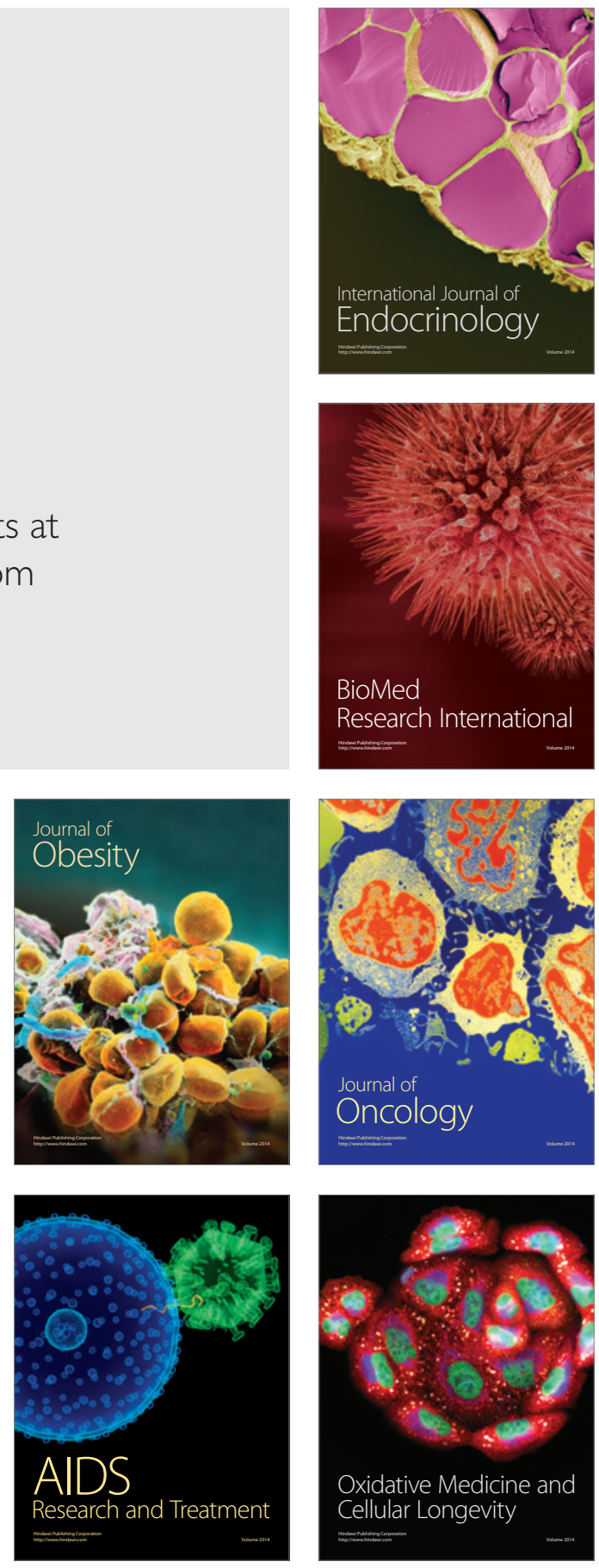